\title{
BMP signaling inhibits intestinal stem cell self-renewal through suppression of $\mathrm{Wnt}-\beta$-catenin signaling
}

\author{
Xi C He ${ }^{1,6}$, Jiwang Zhang ${ }^{1,6}$, Wei-Gang Tong ${ }^{1}$, Ossama Tawfik ${ }^{2}$, Jason Ross ${ }^{1}$, David H Scoville ${ }^{1,2}$, Qiang Tian ${ }^{3}$, \\ Xin Zeng ${ }^{4}$, Xi He ${ }^{4}$, Leanne M Wiedemann ${ }^{1,2}$, Yuji Mishina ${ }^{5}$ \& Linheng $\mathrm{Li}^{1,2}$
}

In humans, mutations in BMPR1A, SMAD4 and PTEN are responsible for juvenile polyposis syndrome ${ }^{1}$, juvenile intestinal polyposis $^{2}$ and Cowden disease ${ }^{3}$, respectively. The development of polyposis is a common feature of these diseases, suggesting that there is an association between BMP and PTEN pathways ${ }^{4,5}$. The mechanistic link between BMP and PTEN pathways and the related etiology of juvenile polyposis is unresolved. Here we show that conditional inactivation of Bmpr1a in mice disturbs homeostasis of intestinal epithelial regeneration with an expansion of the stem and progenitor cell populations, eventually leading to intestinal polyposis resembling human juvenile polyposis syndrome. We show that BMP signaling suppresses Wnt signaling to ensure a balanced control of stem cell self-renewal. Mechanistically, PTEN, through phosphatidylinosital-3 kinase-Akt, mediates the convergence of the BMP and Wnt pathways on control of $\beta$-catenin. Thus, BMP signaling may control the duplication of intestinal stem cells, thereby preventing crypt fission and the subsequent increase in crypt number.

Wnt signaling through $\beta$-catenin promotes cell proliferation ${ }^{6,7}$, and abnormal activation of $\beta$-catenin due to deregulated Wnt signaling leads to adenomatous polyposis coli in intestines ${ }^{6,7}$. The BMP pathway also has a key role during gastrointestinal development ${ }^{8,9}$ and in maintaining tissue homeostasis in the adult ${ }^{10}$. According to current models, BMP2 and BMP4 function by binding to their type II receptor and recruiting type I receptors (Bmprla or Bmprlb). The signal is transduced from the cytoplasm into the nucleus through Smad transcription factors ${ }^{10}$. Activity of BMP can be further regulated by its antagonist, Noggin (encoded by Nog) ${ }^{11}$. Mutations in the tumorsuppressor gene PTEN (a dual protein and lipid phosphatase) ${ }^{12}$ have also been found in gastrointestinal cancers ${ }^{13}$. PTEN is a negative regulator of phosphatidylinosital-3 kinase (PI3K) ${ }^{14}$, which, through Akt (a serine-threonine kinase), promotes cell-cycle progression and suppresses apoptosis. Thus, PTEN inhibits Akt activity and the signals downstream of $\mathrm{Akt}^{13}$.

Intestinal stem cells (ISCs), identified using modified 5-bromodeoxyuridine (BrdU)-retaining assays ${ }^{15}$, are located at the fourth or fifth cell position from the base of each crypt in the small intestine, superior to Paneth cells (Fig. 1a-c). Multipotent ISCs are responsible for generating the entire crypt-villus structure as shown by clonal assays ${ }^{15,16}$. To investigate the role of BMP signaling in regulating intestinal development, we determined the expression patterns of BMP4, its antagonist Noggin, Bmprla and phosphorylated (P-) Smad1, P-Smad5 and P-Smad8 (Fig. 1d-k). BMP4 was expressed in the intravillus and intercrypt mesenchymal cells, including those adjacent to ISCs (Fig. 1d,e). Bmprla had a gradient distribution in epithelial cells along the crypt-villus axis and was also highly expressed in ISCs (Fig. 1f,g) but not in the cells in the proliferating zone (Fig. 1f). Noggin was expressed in the submucosal region adjacent to the crypt bottom and in only some cells in the ISC position or the surrounding cells (Fig. 1h,i). The presence of active BMP signaling was reflected by the presence of P-Smad1, P-Smad5 and P-Smad8 in both villi and ISCs (Fig. 1j,k). Noggin antagonizes BMP signaling to regulate the stem cell niche during neurogenesis ${ }^{17}$. We hypothesized that transient expression of Noggin (Fig. 1h,i) may also function to control ISC properties through regulation of BMP activity.

Because the null mutation of Bmprla is lethal to the embryo ${ }^{18}$, we generated mice in which Bmprla can be conditionally inactivated using the interferon-inducible $M x 1$-cre line ${ }^{19}$. The efficiency of the Mxl-cre line in mediating loxP-dependent DNA excision in the intestine was determined using Z/EG reporter mice ${ }^{20}$. Expression of interferon in $M x 1$-cre mice was induced by injection of polyinosinicpolycytidylic acid (PolyI:C). Clonal expression of enhanced green fluorescent protein (EGFP) was detected in the entire crypt-villus of some units, consistent with previous reports ${ }^{15,16}$. As each unit is generated from a single ISC, clonal expression of EGFP indicates that the PolyI:C-induced gene deletion occurred in the stem cells. In

\footnotetext{
${ }^{1}$ Stowers Institute for Medical Research, 1000 E 50th Street, Kansas City, Missouri 64110, USA. ${ }^{2}$ Department of Pathology and Laboratory Medicine, Kansas University Medical Center, Kansas City, Kansas 66160, USA. ${ }^{3}$ Institute of Systemsbiology, Seattle, Washington 98103 , USA. ${ }^{4}$ Children's Hospital and Harvard University Medical School, Boston, Massachusetts 02115, USA. ${ }^{5}$ Laboratory of Reproductive and Developmental Toxicology, National Institute of Environmental Health Sciences, Research Triangle Park, North Carolina 27709, USA. ${ }^{6}$ These two authors contributed equally to this work. Correspondence should be addressed to L.L. (lil@stowers-institute.org).
} 


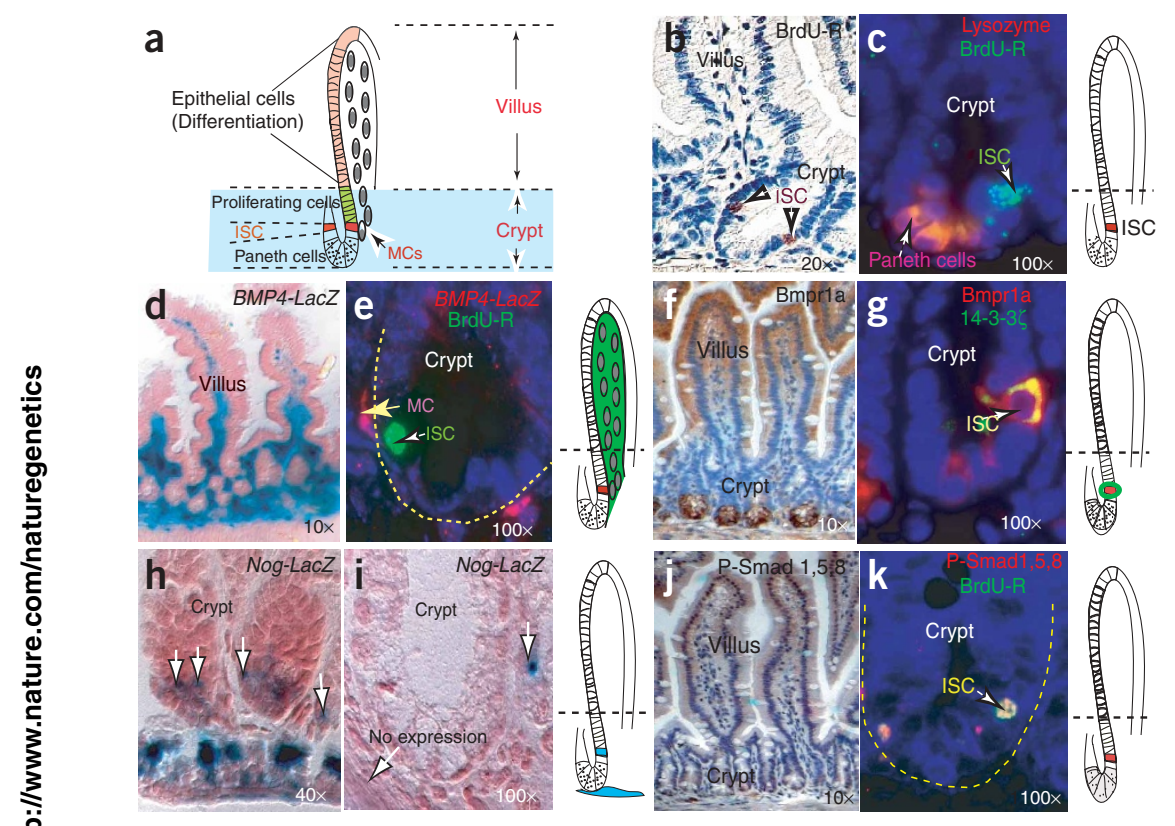

Figure 1 Analyses of intestinal expression patterns of BMP signaling molecules.

(a) Illustration of crypt-villus structure and the positions of stem, Paneth, differentiated epithelial and mesenchymal cells (MCs). $($ b,c) BrdU retention (BrdU-R) $22 \mathrm{~d}$ after treatment labels ISCs, located above the Paneth cells, which are stained by antibody to lysozyme. (d,e) BMP4 is detected (by the presence of galactosidase) in the mesenchymal cells (MC), particularly those adjacent to ISCs recognized by BrdU retention (BrdU-R). (f,g) Bmprla is found at varying levels in epithelial cells in the different crypt-villus regions and in the ISCs. Due to incompatibility of antibody staining, Bmprla was costained with 14-3-3 $\zeta$, which specifically stains cells recognized with P-PTEN (data not shown), an ISC marker (see Fig. 3f). (h) When expressed, Noggin is restricted to the basement membrane adjacent to the crypt and in some ISCs or their surrounding cells (white arrows). (i) Noggin expression is transient. (j,k) Distribution of $\mathrm{P}$ Smad1, P-Smad5 and P-Smad8 along the villuscrypt axis and in ISCs. BrdU-R, BrdU retention.

윽 contrast, the cells emanating from ISCs that escape targeting retain LacZ expression (Fig. 2a,b).

The 15 Bmprla mutant mice that we analyzed all developed O multiple polyps (15-40 polyps in the segment located $15-25 \mathrm{~cm}$ from the pylorus; Fig. 2c,d), and successful targeting of Bmprla was confirmed by loss of P-Smad1, P-Smad5 and P-Smad8 (Fig. 2e,f). The polyps ranged from diminutively small and sessile (averaging $0.2 \mathrm{~mm}$ in diameter) to large and pedunculated (averaging $2 \mathrm{~mm}$ in diameter). Histopathological analyses of early-stage polyps in the intestinal tract showed general overgrowth of intestinal tissue with an increased number of crypts and fused villi. At later stages, the polyps developed into structures with cystically dilated and distorted glands, some filled (2) with mucin and inflammatory cells with surrounding fibrous stroma

(Fig. 2d). These late-stage polyps had a histology similar to that seen in human juvenile polyposis syndrome ${ }^{1}$.

We observed severe gastrointestinal defects in the Bmprla mutant mice, which prompted us to determine how intestinal development is affected. In wild-type mice, proliferating cells were located in the upper crypt region where Bmprla is absent (compare Fig. 1f with Fig. 2g), as identified by Ki67 presence. In Bmprla mutant mice, the proliferating cell population was expanded substantially, primarily owing to the

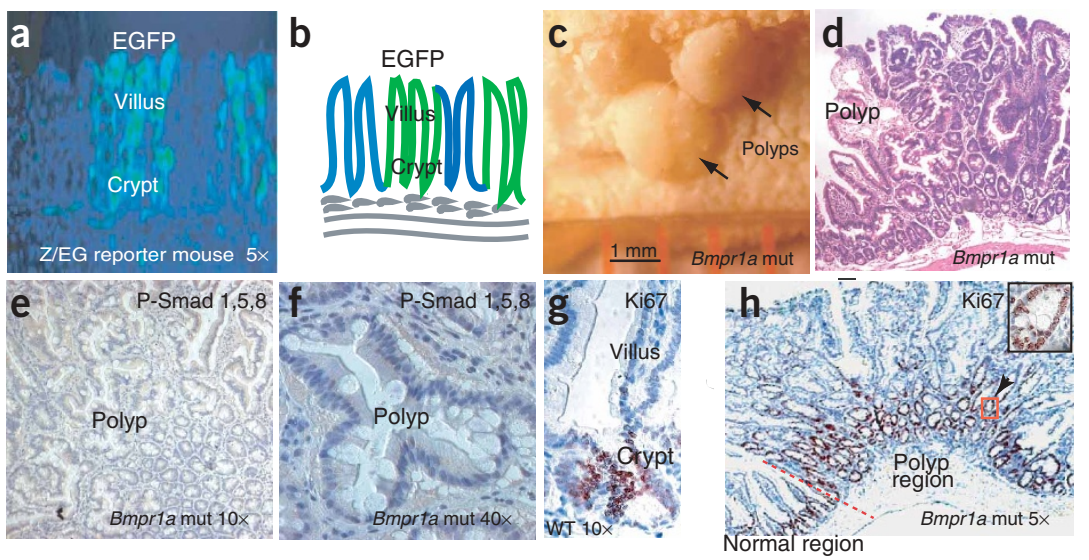

increase in the number of crypts in the polyp region (Fig. 2h). This result suggests that BMP signaling restricts crypt cell fate.

Wnt signaling normally favors crypt cell fate over villus differentiation $^{6,7,9}$. The increased number of crypts suggested that Wnt signaling might be affected in the intestines of Bmprla mutant mice. We therefore compared Wnt signaling, as measured by the level of activated (phosphorylated) LRP6 (P-LRP6), in wild-type and Bmprla mutant mice. LRP6, a coreceptor for Wnt, becomes phosphorylated upon Wnt binding ${ }^{21}$ and serves as a marker for active Wnt signaling. Wnt signaling was active in normal intestinal crypts (Fig. 3a) and in the polyp crypts of Bmprla mutant mice (Fig. 3b). We also measured the transcriptional activity of $\beta$-catenin by electroporating, into cultured intestinal segments, a reporter plasmid bearing TCF- $\beta$-catenin binding sites $(T o p)^{22}$ driving a short-lived mutant of green fluorescent protein (GFP; Top-d2GFP). $\beta$-catenin transcriptional activity was detected primarily in the ISCs, despite the widespread presence of an active Wnt signal (as measured by P-LRP6) in the progenitor cells of crypts (Fig. 3c,d). This observation led us to hypothesize that Wnt signaling is required for the nuclear activity of $\beta$-catenin but is not sufficient to fully activate $\beta$-catenin in ISCs, particularly when BMP signaling is active (Fig. 1k).

Inactivation of PTEN has been reported to activate Akt and the subsequent nuclear accumulation of $\beta$-catenin ${ }^{23}$, suggesting that the PTEN-Akt pathway might regulate $\beta$-catenin activity in ISCs. We therefore analyzed both PTEN and the inactive (phosphorylated)

Figure 2 Test of the efficiency of Polyl:Cinduced gene deletion and polyposis phenotype. (a,b) Targeting efficiency was assayed in Mx1-cre Z/EG chimeric mice. (c,d) Polyps in small intestine and the corresponding histological sections. (e,f) Loss of expression of P-Smad1, P-Smad5 and P-Smad8. (g,h) Ki67 staining to locate the proliferation zone in intestinal sections from wild-type (WT) and Bmprla mutant (mut) mice. 
Figure 3 Expression of P-LRP6, P-PTEN, P-Akt and $\beta$-catenin in crypts and stem cell compartment in intestinal segments, and detection of transcriptional activity of $\beta$-catenin. $(\mathbf{a}, \mathbf{b})$ LRP6 is predominantly detected in crypts of wild-type and mutant intestines (white arrow). (c) Costaining of P-LRP6 with BrdU retention in ISCs. (d) Detection of Top-d2GFP in P-PTEN ${ }^{+}$ ISCs. (e-h) Detection of P-PTEN and P-Akt in ISCs and costaining of cells retaining BrdU (BrdU-R) with P-PTEN or P-Akt in small

retention (BrdU-R) and P-PTEN. (k,I) Detection of nuclearly accumulated $\beta$-catenin in dividing ISCs, recognized by BrdU retention (BrdU-R). ( $m-\mathbf{0}$ ) Detection of transcriptional activity of $\beta$-catenin in ISCs in Top-GAL transgenic mice. Antibody to galactosidase was used to stain a frozen section.

Due to incompatibility of antibodies, ISCs were

recognized by 14-3-3 , which specifically costains P-PTEN. (p) Western-blot assays to measure the protein levels of P-PTEN and P-Akt in intestines of wild-type and Bmprla mutant mice. (q-s) Detection of stem cell duplication in polyp region of intestines of Bmprla mutant mice, as recognized by P-PTEN, P-Akt and nuclearly-localized $\beta$-catenin, respectively. ( $t$ ) Representation of crypt fission in polyp region of intestines of Bmprla mutant mice. mut, Bmprla mutant mice; WT, wild-type mice.

form of PTEN (P-PTEN) ${ }^{24}$ in intestines of wild-type mice and found that P-PTEN was present specifically in ISCs (Fig. 3e). We detected P-PTEN in BrdU-retaining ISCs (Fig. 3f), supporting this conclusion. We also detected phosphorylated Akt (P-Akt) in BrdU-retaining ISCs (Fig. 3g,h), consistent with the role of PTEN as a negative regulator of $\mathrm{Akt}^{14}$. We then asked whether the PTENAkt pathway affects $\beta$-catenin activity in ISCs. We observed that $\beta$-catenin was associated with the membrane in quiescent ISCs (Fig. 3i) but was found in the nucleus of P-PTEN $^{+}$ISCs (Fig. 3j). This nuclear localization of $\beta$-catenin correlates with the activation of Top-d2GFP reporter plasmid in P-PTEN $^{+}$ISCs (Fig. 3d). We also found nuclearly localized $\beta$-catenin in dividing (BrdU-retaining) ISCs (Fig. 3k,l). Furthermore, analysis of Top-GAL ${ }^{25}$ transgenic mice showed that in vivo $\beta$-catenin signaling was active in ISCs, including those actively dividing (Fig. $\mathbf{3 m - o}$ ). Taken together, these data support the idea that nuclearly localized $\beta$-catenin has a role in promoting ISC division. Thus, inactive PTEN (P-PTEN), through Akt, may coordinate with the Wnt signal to fully activate $\beta$-catenin in ISCs.

We next asked what signal controls PTEN activity. Genetic evidence suggests that there is an association between the BMP and PTEN pathways ${ }^{4}$, and the BMP signal has been shown to enhance PTEN activity ${ }^{5}$. Western-blot analysis showed that levels of P-PTEN and P-Akt were 4-5 times higher in three Bmprla mutant mice than in wild-type mice (Fig. 3p), suggesting that BMP inhibits Akt activity through regulation of PTEN activity. We further examined the levels of P-PTEN and P-Akt in ISCs when BMP signaling is blocked. We detected only a single ISC in the ISC position in wild-type crypts (Fig. 3e-h) but detected two side-by-side, aligned ISCs in a portion of
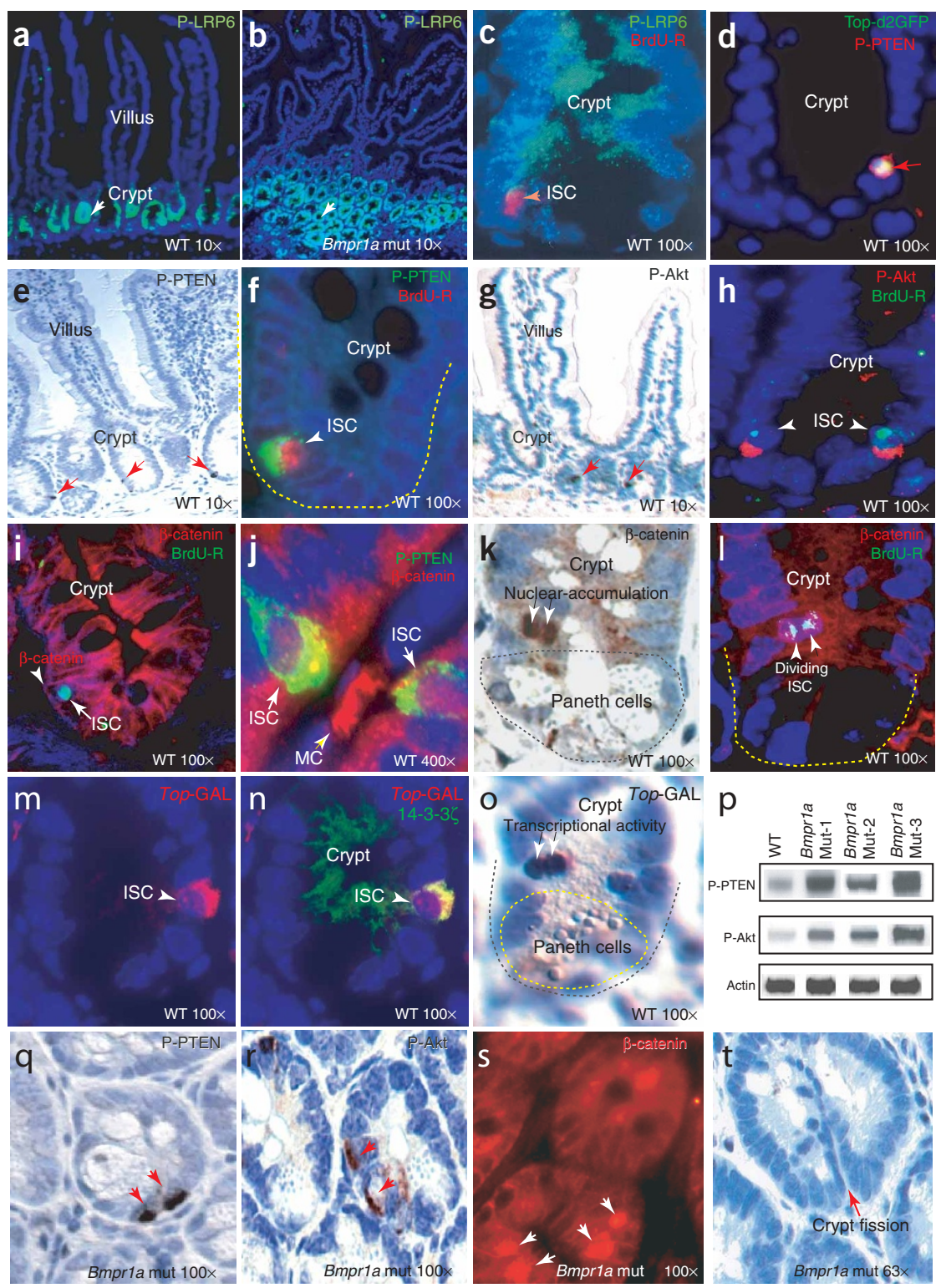

the crypts in the polyp regions in Bmprla mutant mice, as identified by the presence of P-PTEN or P-Akt (Fig. 3q,r; see below for ISC number quantification). This observation indicates that BMP signaling regulates the PTEN-Akt pathway in ISCs. We considered whether $\beta$-catenin activity changed correspondingly in Bmprla mutant mice. The presence of doublet cells showing nuclear localization of $\beta$-catenin (Fig. 3s) in the polyp region further supports the interpretation that nuclear accumulation of $\beta$-catenin in ISCs is inhibited by BMP signaling by regulating PTEN activity. We also observed crypt fission in the polyp region of Bmprla mutant mice (Fig. 3t).

Therefore, a second signal must abrogate BMP and coordinate with Wnt to fully activate $\beta$-catenin in ISCs. To address this, we also analyzed the effect of Noggin on levels of P-PTEN and P-Akt and on the subcellular localization of $\beta$-catenin in ex vivo cultured intestine (Fig. 4a-1). Treatment with Noggin increased the levels of P-PTEN and P-Akt and led to the relocation of $\beta$-catenin to the nucleus (Fig. 4c,g,k), although western blotting showed that the total amount of $\beta$-catenin in cells did not change substantially (Supplementary Fig. 1 online). A PI3K inhibitor, Ly294002, antagonized the effect of 

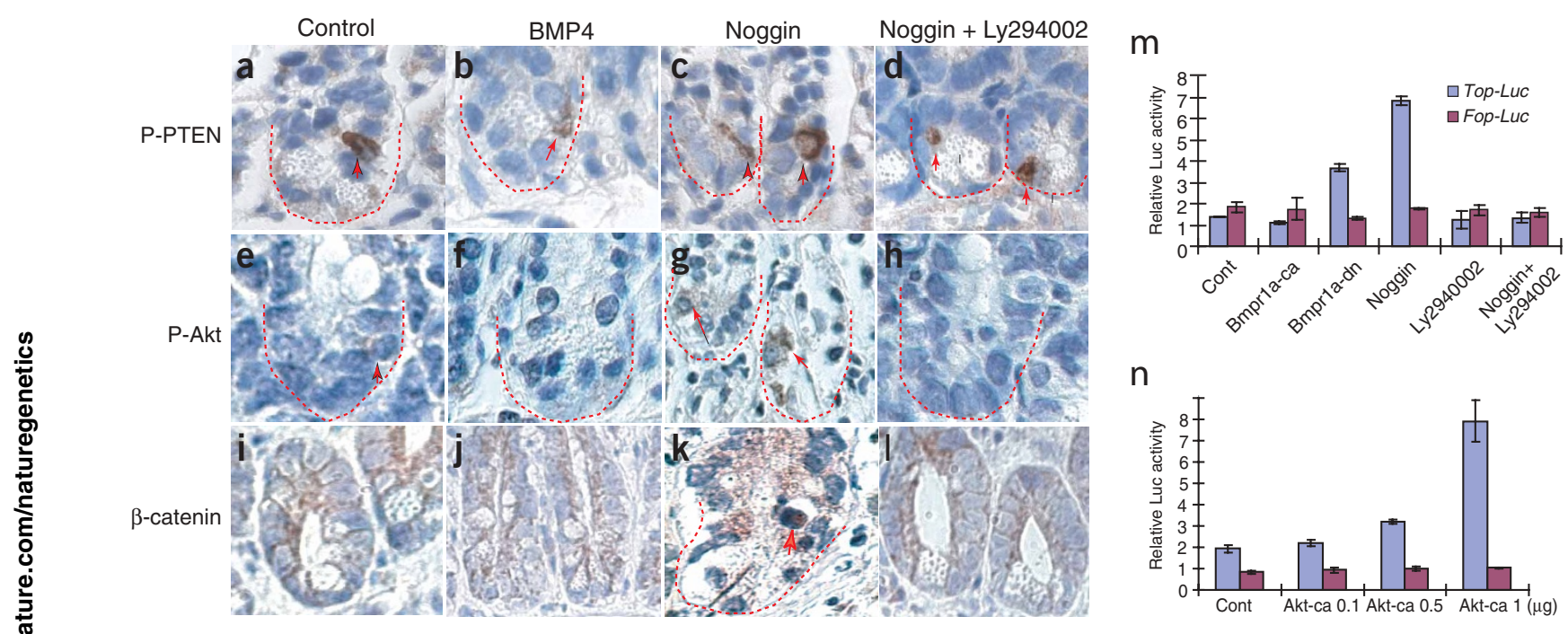

Figure 4 Analysis of PTEN, Akt and $\beta$-catenin activity. (a-I) Analysis of changes in expression of P-PTEN and P-Akt, and cellular localization of $\beta$-catenin in the crypt under different conditions in ex vivo cultured intestinal segments. Red arrows indicate the detected molecules in the stem cell compartment. $(\mathbf{m}, \mathbf{n})$ Transfection assay to test the regulation of $\beta$-catenin activity by constitutively activated Bmprla (Bmprla-ca), dominant-negative Bmprla (Bmprla$\mathrm{dn}$ ), Noggin and constitutively active Akt (Akt-ca) using Top-Luc reporters.

Noggin on nuclear relocalization of $\beta$-catenin (Fig. 4l), arguing that this regulation is mediated through the PTEN-Akt pathway.

Further supporting the idea that BMP has a role in regulating $\beta$-catenin transcriptional activity through PTEN and Akt, exposure to Noggin or expression of dominant-negative Bmprla activated $\beta$-catenin activity, whereas expression of constitutively activated Bmprla or treatment with Ly294002 inhibited $\beta$-catenin activity as assayed by Top-Luc (luciferase) activity (Fig. $\mathbf{4 m}$ ). We also tested the direct regulation of $\beta$-catenin activity by Akt. Constitutively active Akt also enhanced $\beta$-catenin activity in a dosage-dependent manner (Fig. 4n). These results provide further evidence supporting our hypothesis that $\beta$-catenin activity can be regulated by BMP signaling through Bmprla and the PI3K-Akt pathway.

BMP signaling may therefore have a role in inhibiting ISC selfrenewal by inhibiting $\beta$-catenin activity, thereby balancing the role of Wnt- $\beta$-catenin in promoting stem cell self-renewal ${ }^{26}$. If this hypothesis is correct, then we would anticipate an increase in the self-renewal capacity of ISCs when the BMP signal is blocked. We therefore examined the stem cell zone in multiple crypts of the polyp regions in Bmprla mutant mice. We compared the number of ISCs in equal lengths $(670 \mu \mathrm{m})$ of intestinal sections from nine normal regions of three wild-type mice and five polyp regions of three Bmpr1a mutant mice (Table 1); ISCs were recognized by P-PTEN. We found that, on average, there were $\sim 3.1$ times more crypts in polyp regions $(47 \pm$ 3.8 crypts; mean \pm s.d.) than in normal regions ( $14.8 \pm 1.1$ crypts; mean \pm s.d.) of intestines of Bmprla mutant mice. This increase in crypt number was accompanied by a $\sim 1.6$-fold increase in the number of ISCs per crypt. This resulted in a $\sim 5$-fold increase in the average number of ISCs in Bmprla mutant mice compared with wild-type mice. Taken together, these results suggest that BMP signaling has a role in inhibiting ISC self-renewal by regulating PTEN activity, consistent with previous reports that inactivation of PTEN leads to activation of PI3K-Akt and results in expansion of embryonic and neural stem cell populations ${ }^{27,28}$.

BMP signaling was recently reported to repress crypt formation and polyp growth in Nog transgenic mice by inhibiting Wnt signaling9. Using a Bmprla mutant model, we obtained similar findings and further explored the underlying mechanisms. We are not excluding the possibility that inactivation of Bmprla affects the canonical BMP-Smad pathway, which may control expression of Wnt or Frizzled proteins and may also regulate epithelial differentiation and apoptosis. That pathway may, in part, contribute to the development of polyposis (as mutations in SMAD4 also lead to polyp formation) ${ }^{2}$. But our data clearly show that PTEN, through PI3K-Akt, mediates the convergence of the BMP and Wnt pathways on control of $\beta$-catenin activity, thereby ensuring a balanced control of ISC self-renewal (Supplementary Fig. 2 online). Wnt signaling, as detected by P-LRP6, is active not only in stem cells but in all the proliferating cells. We also found that nuclearly localized $\beta$-catenin and the underlying transcriptional activity of $\beta$-catenin are primarily associated with P-PTEN in ISCs. These observations suggest that Wnt signaling is required for stem cell activation and self-renewal but is not sufficient. A second signal is therefore required for stem cell activation. We propose that this second signal is dependent on the transient expression of Noggin and is required to override the BMP signal, releasing the inhibition of $\beta$-catenin by PTEN and thus coordinating with Wnt signaling to activate stem cells (Supplementary Fig. 2 online). Supporting this idea, the Noggin-Wnt coordination has also been reported to be required for initiation of the hair growth cycle $^{29}$. Finally, it has been proposed that crypt fission (duplication) is triggered by stem cell duplication ${ }^{30}$. In this study, we document the correlation between stem cell duplication (Fig. 3q-s) and crypt number increase, suggesting that BMP signaling may control crypt fission

\section{Table 1 Quantification of ISCs}

\begin{tabular}{lccc}
\hline & Wild-type (9) & Polyp (5) & Relative increase \\
\hline Crypts & $14.8 \pm 1.1$ & $47 \pm 3.8$ & $\sim 3.1$ \\
P-PTEN $^{+}$cells* & $5.7 \pm 1$ & $28.6 \pm 3.9$ & $\sim 5.0$ \\
Detectable ISCs/Crypt & 0.38 & 0.6 & $\sim 1.6$
\end{tabular}

Numbers of cells (mean \pm s.d.) in equal lengths of intestinal segments $(670 \mu \mathrm{m})$ of regions of polyps from mutant mice and normal regions from wild-type mice. *This is the number of detectable ISCs, as not all ISCs are in the same layer of different crypts. 
(Fig. 3t) through inhibition of stem cell self-renewal and their subsequent duplication.

\section{METHODS}

Inducible Cre expression. We injected mice intraperitoneally with PolyI:C ( $250 \mu \mathrm{g}$ per mouse) on days 21,23 and 25 . Four to six months after injection, we found polyps in the small intestines, from the jejunum to the ileum (15-25 cm measured from the pylorus). The animal protocol used in these studies was approved by the Institutional Animal Care and Use Committee at Stowers Institute.

Intestinal specimen preparation and immunohistochemical staining. We collected specimens from the small intestines (segments $15-25 \mathrm{~cm}$ below the pylorus) of mutant and wild-type mice. We prepared specimens and carried out immunochemical and immunofluorescent stainings following standard procedures (Supplementary Methods online). We carried out X-gal staining for detection of lac $Z$ expression as described ${ }^{20}$.

BrdU retaining assay ${ }^{15}$. We irradiated $\mathrm{C} 57 \mathrm{~B} 6 / \mathrm{L}$ and BMP4-lacZ mice (aged 6-8 weeks; 8 Gy) and injected them intraperitoneally with $\operatorname{BrdU}$ (10 mg per kg body weight) three times a day for $2 \mathrm{~d}$ (ref. 15). We collected intestinal specimens 8, 22 and $40 \mathrm{~d}$ after BrdU administration. We counted non-Paneth BrdU-retaining cells per small intestine cross-sections containing $~ 84$ crypts (hereafter called circumferences) $)^{15}$ : there were 2.0 on day 8 (18 retaining cells per nine circumferences), 1.8 on day 22 (16 retaining cells per nine circumferences) and 1.0 on day 40 (9 retaining cells per nine circumferences). These numbers are similar to those observed previously in ${ }^{3} \mathrm{H}$-thymidine labeling experiments ${ }^{15}$. We carried out BrdU in situ staining using a staining kit (Zymed Laboratories). We collected BrdU data on day 22.

Ex vivo culture. We carried out intestinal culture in 50\% DMEM-1 medium without calcium (Biosource), 40\% supplemented F-12/ Mixture (Biosource), $10 \%$ fetal bovine serum, 1\% Pen-Strep and 1\% Fungizone plus $50 \mu \mathrm{M}$ Ly294002 (Sigma) and $25 \mathrm{ng} \mathrm{m}^{-1}$ of Noggin or BMP4 (R\&D system) as indicated. We soaked AffyGel blue beads (100-200 mesh, BioRad) in $500 \mu \mathrm{g} \mathrm{ml}^{-1}$ of Noggin or BMP4 and then injected them into 0.5-inch intestinal segments (10 beads per segment). We introduced DNA by electroporation (Square Electroporator CUY-21, BEX). We injected $100 \mu \mathrm{g}$ of Topd2GFP (Sin-18.ppt.ot-EGFP) into 0.5-inch intestinal segments submerged in phosphate-buffered saline and applied five pulses $(20 \mathrm{~V}$ and $50 \mathrm{~ms})$.

Transfection assay. We transfected IEC18 cells using Lipofectamine (Invitrogen) with $1 \mu \mathrm{g}$ of Top-Luc, $1 \mu \mathrm{g}$ of Fop-Luc (Upstate) or $0.1 \mu \mathrm{g}$ of TK-LPR (internal control; Invitrogen) and plasmids as indicated. Twelve hours after transfection, we treated the cells with Noggin and Ly294002 separately or in combinations for another $8 \mathrm{~h}$. We then collected cells for luciferase assays (Dual-Luciferase Reporter Assay System; Promega, E1910).

Western-blot analysis. We homogenized intestinal tissue in a cocktail of $1 \mathrm{ml}$ lysis buffer (100 mM Tris- $\mathrm{HCl}(\mathrm{pH} 6.8), 2 \%$ SDS and a proteinase inhibitor cocktail supplied by Roche). The supernatant was collected after centrifugation. We fractionated protein extracts $(25 \mu \mathrm{g}$ per well) on SDS-PAGE gels and transferred them onto nitrocellulose membrane. The membrane was blocked using casein blocker (Pierce) and incubated with the appropriate dilutions of primary and secondary antibodies in casein blocker. We developed the membrane after washing it with TBST solution (Tris-buffered saline plus 0.05\% Tween-20) and chemiluminescent reagents (Santa Cruz).

Note: Supplementary information is available on the Nature Genetics website.

\section{ACKNOWLEDGMENTS}

We thank P. Dijke for providing antiserum to Bmprla; A. McMahon, B. Hogan and C.G. Lobe for providing Nog-lacZ, BMP4-lacZ and Z/EG mice, respectively; I. Weissman and L. Alies for providing Top-d2GFP; B. Li for providing the constitutively active Akt plasmid; S. Harris for providing the constitutively activated and dominant-negative Bmprla cDNAs; S. Hawley and R. Krumlauf for scientific discussions; J. Haug for suggestions; J. Conaway, O. Pourquié, S. Abmayr, P. Trainor and H. Lin for their comments regarding the manuscript; P. Trainor and A. Iulianella for assistance with the intestinal tissue culture experiments; S. Hawley, W. Cui and J. Kramer for technical advice; D. di Natale for assistance on manuscript editing; P. Kulesa and D. Stark for imaging assistance; T. Johnson and D. Grant for histological assistance; and J. William and S. Barrett for technical assistance. This work was supported by Stowers Institute for Medical Research.

\section{COMPETING INTERESTS STATEMENT}

The authors declare that they have no competing financial interests.

Received 1 June; accepted 24 August 2004

Published online at http://www.nature.com/naturegenetics/

1. Howe, J.R. et al. Germline mutations of the gene encoding bone morphogenetic protein receptor 1A in juvenile polyposis. Nat. Genet. 28, 184-187 (2001).

2. Howe, J.R. et al. Mutations in the SMAD4/DPC4 gene in juvenile polyposis. Science 280, 1086-1088 (1998)

3. Liaw, D. et al. Germline mutations of the PTEN gene in Cowden disease, an inherited breast and thyroid cancer syndrome. Nat. Genet. 16, 64-67 (1997).

4. Waite, K.A. \& Eng, C. From developmental disorder to heritable cancer: it's all in the BMP/TGF-beta family. Nat. Rev. Genet. 4, 763-773 (2003).

5. Waite, K.A. \& Eng, C. BMP2 exposure results in decreased PTEN protein degradation and increased PTEN levels. Hum. Mol. Genet. 12, 679-684 (2003).

6. Miyoshi, Y. et al. Germ-line mutations of the APC gene in 53 familial adenomatous polyposis patients. Proc. Natl. Acad. Sci. USA 89, 4452-4456 (1992).

7. Sancho, E., Batlle, E. \& Clevers, H. Live and let die in the intestinal epithelium. Curr. Opin. Cell Biol. 15, 763-770 (2003).

8. Roberts, D.J. Molecular mechanisms of development of the gastrointestinal tract. Dev. Dyn. 219, 109-120 (2000).

9. Haramis, A.P. et al. De novo crypt formation and juvenile polyposis on BMP inhibition in mouse intestine. Science 303, 1684-1686 (2004).

10. Itoh, S., Itoh, F., Goumans, M.J. \& Ten Dijke, P. Signaling of transforming growth factor-beta family members through Smad proteins. Eur. J. Biochem. 267, 6954 6967 (2000).

11. McMahon, J.A. et al. Noggin-mediated antagonism of BMP signaling is required for growth and patterning of the neural tube and somite. Genes Dev. 12, 1438-1452 (1998).

12. Besson, A., Robbins, S.M. \& Yong, V.W. PTEN/MMAC1/TEP1 in signal transduction and tumorigenesis. Eur. J. Biochem. 263, 605-611 (1999).

13. Mutter, G.L. Pten, a protean tumor suppressor. Am. J. Pathol. 158, 1895-1898 (2001).

14. Stambolic, V. et al. Negative regulation of PKB/Akt-dependent cell survival by the tumor suppressor PTEN. Cell 95, 29-39 (1998).

15. Potten, C.S., Owen, G. \& Booth, D. Intestinal stem cells protect their genome by selective segregation of template DNA strands. J. Cell Sci. 115, 2381-2388 (2002).

16. Roth, K.A., Hermiston, M.L. \& Gordon, J.I. Use of transgenic mice to infer the biological properties of small intestinal stem cells and to examine the lineage relationships of their descendants. Proc. Natl. Acad. Sci. USA 88, 9407-9411 (1991).

17. Lim, D.A. et al. Noggin antagonizes BMP signaling to create a niche for adult neurogenesis. Neuron 28, 713-726 (2000).

18. Mishina, Y., Suzuki, A., Ueno, N. \& Behringer, R.R. Bmpr encodes a type I bone morphogenetic protein receptor that is essential for gastrulation during mouse embryogenesis. Genes Dev. 9, 3027-3037 (1995).

19. Zhang, J. et al. Identification of the haematopoietic stem cell niche and control of the niche size. Nature 425, 836-841 (2003).

20. Novak, A., Guo, C., Yang, W., Nagy, A. \& Lobe, C.G. Z/EG, a double reporter mouse line that expresses enhanced green fluorescent protein upon Cre-mediated excision. Genesis 28, 147-155 (2000).

21. Tamai, K. et al. LDL-receptor-related proteins in Wnt signal transduction. Nature $\mathbf{4 0 7}$, 530-535 (2000).

22. Korinek, V. et al. Constitutive transcriptional activation by a beta-catenin-Tcf complex in APC-I- colon carcinoma. Science 275, 1784-1787 (1997).

23. Persad, S., Troussard, A.A., McPhee, T.R., Mulholland, D.J. \& Dedhar, S. Tumor suppressor PTEN inhibits nuclear accumulation of beta-catenin and T cell//ymphoid enhancer factor 1-mediated transcriptional activation. J. Cell Biol. 153, 1161-1174 (2001).

24. Vazquez, F., Ramaswamy, S., Nakamura, N. \& Sellers, W.R. Phosphorylation of the PTEN tail regulates protein stability and function. Mol. Cell Biol. 20, 5010-5018 (2000).

25. Merrill, B.J., Gat, U., DasGupta, R. \& Fuchs, E. Tcf3 and Lef1 regulate lineage differentiation of multipotent stem cells in skin. Genes Dev. 15, 1688-1705 (2001).

26. Reya, T. et al. A role for Wnt signalling in self-renewal of haematopoietic stem cells. Nature 423, 409-414 (2003)

27. Groszer, M. et al. Negative regulation of neural stem/progenitor cell proliferation by the Pten tumor suppressor gene in vivo. Science 294, 2186-2189 (2001).

28. Kimura, T. et al. Conditional loss of PTEN leads to testicular teratoma and enhances embryonic germ cell production. Development 130, 1691-1700 (2003).

29. Jamora, C., DasGupta, R., Kocieniewski, P. \& Fuchs, E. Links between signal transduction, transcription and adhesion in epithelial bud development. Nature $\mathbf{4 2 2}$ 317-322 (2003).

30. Brittan, M. \& Wright, N.A. Gastrointestinal stem cells. J. Pathol. 197, 492-509 (2002). 